\title{
SAÚDE E MEMÓRIA NAS PÁGINAS DA RADIS: O PASSADO SE FAZ PRESENTE
}

\section{HEALTH ND MEMORY IN THE PAGES OF RADIS: THE PAST IS PRESENT}

\author{
Izamara Bastos MACHADO $^{1}$; Wilson Couto BORGES ${ }^{2}$; Ana Paula Goulart RIBEIRO ${ }^{3}$
}

\section{Resumo}

Este artigo propõe uma discussão sobre a produção de memórias da saúde pública brasileira a partir das narrativas jornalísticas da revista Radis (revista publicada pela Fundação Oswaldo Cruz). Consideramos que a memória e os sentidos produzidos sobre a saúde pública nas edições de Radis diferem daqueles mobilizados pelas revistas e jornais comerciais brasileiros. Entendemos que sua entrada no jogo da memória efetiva-se por um projeto que tem no Sistema Único de Saúde (SUS) as bases de sua ação, acionando lógicas e procedimentos próprios aos seus universos de interesse e de construção identitária.

Palavras-chaves: jornalismo, memória, narrativas, saúde pública, SUS.

\begin{abstract}
This article proposes a discussion about the production of memories of Brazilian public health from the journalistic narratives of Radis magazine (journal published by the Oswaldo Cruz Foundation). We believe that the memory and senses produced on public health in Radis editions differ from those mobilized by Brazilian trade magazines and newspapers. We understand that its entry into the memory game is effective because of a project that has in the Brazilian Unified Health System (SUS) the bases of its action, triggering logics and procedures proper to its universes of interest and identity construction.
\end{abstract}

Keywords: journalism, memory, narratives, public health; SUS.

\footnotetext{
${ }^{1}$ Doutoranda em Comunicação e Cultura pela UFRJ. Pesquisadora no Laboratório de Pesquisa em Comunicação e Saúde do ICICT/FIOCRUZ. E-mail: bastos.iza@ gmail.com

${ }^{2}$ Doutor em Comunicação e Mestre em Ciência Política (UFF). Professor e Coordenador do Programa de Pós-Graduação em Informação, Comunicação e Saúde (PPGICS) da Fundação Oswaldo Cruz. E-mail: wcborges1@yahoo.com.br

${ }^{3}$ Doutora em Comunicação e Cultura pela Universidade Federal do Rio de Janeiro(ECO-UFRJ). Pósdoutora em História Contemporânea pela Universidade de Grenoble, na França. Professora da ECO/UFRJ. Coordena o Projeto Memória do Jornalismo Brasileiro e o grupo de pesquisa Mídia, Memória e Temporalidades, do Núcleo de Estudos e Projetos em Comunicação da UFRJ. E-mail: goulartap@gmail.com
} 
Introdução

Embora partamos da premissa de que memória e esquecimento são dispositivos operados em inter-relação, isto é, não se pode pensar na memória sem que nela esteja contida a dimensão do esquecimento (POLLAK, 1989; RICOEUR, 1994; 2003; RIBEIRO, 1995; BARBOSA, 2007), nossa opção no presente artigo é: (a) evidenciar o papel da primeira à luz de sua relação com a construção de uma identidade, que emerge de um jogo dialético e processual originado de situações, posições, interações, e, paralelamente, (b) destacar que ela só existe, em última instância, enquanto discurso, enquanto narrativa. Isso significa assumir desde já que a memória é uma atividade produtora que se realiza dentro de certas regras culturais.

Nessa direção, também se torna fundamental a identificação dos mecanismos pelos quais a memória é construída: como uma atividade criativa que se inscreve entre a dimensão do verossímil, somada a um regramento (imaginação regrada), por um lado, investida no imaginário social, por outro. Entretanto, não queremos dizer com isso que esse complexo jogo da memória seja uma determinação que se exerce contra os atores sociais. No limite, e concordamos com Ricoeur (1994), é o leitor quem valora uma leitura, que dá sentido a ela. Porém, também julgamos não ser possível negar que, face às disputas em torno do processo de lembrar/esquecer, certo "controle" sobre a memória contribui para que o interlocutor responda aos estímulos propostos de maneira mais ou menos homogênea.

Há um terceiro aspecto que também merece ser sublinhado na exposição de nossos argumentos: a escolha do ator social. Nossa escolha pela revista Radis $^{4}$ como objeto de investigação é justificada, em primeiro lugar, pelo fato de ser um periódico - e aqui hipótese central é a de que, como narrativa (jornalística), seus enunciados misturam o real e o ficcional (BORGES, 2014) a partir de um imaginário social sobre o campo sanitário de forma a interferir na maneira como a saúde é evocada; em segundo lugar, como ela se apresenta - como uma publicação que tem o explícito desejo de produzir memórias e

\footnotetext{
${ }^{4}$ A revista Radis faz parte do Programa Radis de Comunicação e Saúde - um programa nacional e permanente da Escola Nacional de Saúde Pública (ENSP), da Fundação Oswaldo Cruz (Fiocruz), iniciado em 1982. Mais adiante apresentaremos a revista de uma maneira mais detalhada.
} 
colaborar com a história da saúde pública; em terceiro, a forma como a saúde é lembrada - eventos do passado são rememorados no tempo presente através do controle de seu acervo, colocando-se como "guardião" da memória da saúde no Brasil.

Por último, nossas reflexões apontam, no campo das hipóteses, para uma imbricação entre a construção da memória, no caso daquela exercida pela Radis, e os princípios do Sistema Único de Saúde (SUS): universalidade, integralidade, equidade. Tal como exploraremos nas próximas páginas, a ação mnemônica aqui apresentada toma como uma das suas bases a estreita relação entre uma publicação comprometida com uma saúde pública de qualidade, democrática e cidadã. Nesses termos, memória e universalidade na direção de oferecer fatos e histórias que abarquem o processo de construção da saúde no Brasil; memória e integralidade com o objetivo de permitir a percepção da construção de uma arquitetura do sistema para além das denúncias tão presentes na chamada grande imprensa; e, memória e equidade estariam intimamente ligadas na medida em que o movimento da revista busca dar à população elementos ausentes de uma memória oficial (ou difundida pela chamada imprensa comercial) observando as necessidades daí derivadas.

\section{Memória: ação do presente de atualizar o passado para interferir no futuro}

Como já antecipamos brevemente na introdução, estamos entendendo a produção da memória como constitutiva de um processo dinâmico e contínuo que, especialmente a partir dos discursos dos meios de informações jornalísticas, se efetiva com uma construção que, sob a égide da notícia ou da reportagem, mistura o real e o ficcional. Tais construções encontram ressonância no tecido social uma vez que dialogam com determinadas convenções que ajudam a sedimentar processos sociais que são interiorizados pelos indivíduos. Com essa perspectiva, é oportuno trazer para esse debate algumas reflexões de Paul Ricoeur, especialmente aquela vinculada à proposição de que toda narrativa se apresenta como um fio condutor da ação humana. Indo adiante, o autor defende que a ação humana se revela através da história narrada.

Para Ricoeur, como a vida humana é um texto que produz sentidos, ela pode ser interpretada, principalmente por intermédio da leitura/compreensão do significar humano 
que se revela através das metáforas. Essa é a proposição do pensador francês em sua obra de síntese - Tempo e Narrativa (RICOEUR, 1994). Na perspectiva aberta pelo autor, o tempo só existe na linguagem. Ou seja, só existe materialmente através da narrativa, enquanto o ato de narrar, como característica comum da experiência humana, se revela pelo caráter temporal. Para ele, como os relatos com pretensão de verdade e os relatos ficcionais se embaralham, não apresentando fronteiras fixas, haveria uma unidade ficcional entre modos e gêneros narrativos: o tempo. Assim, o autor estabelece a reciprocidade entre narratividade e temporalidade. Melhor dizendo, seria pela linguagem que se resolveriam as aporias agostinianas e as contribuições aristotélicas, pela reciprocidade e temporalidade, num terceiro tempo - o tempo da narrativa. Paul Ricoeur é fundamental na presente reflexão, pois, será ele quem apontará que a memória, em última instância, só existe enquanto narrativa. Narrativa que se revela na tessitura da intriga: uma atividade produtora que se realiza dentro de certas regras culturais.

A hipótese central da reflexão de Ricoeur é que a necessidade de materialização do tempo, através de uma atividade produtora - a ação de narrar -, é uma necessidade humana. Para ele, existe uma unidade ficcional entre os modos e gêneros narrativos: o tempo. Dessa forma, o filósofo dos sentidos parte das reflexões de Santo Agostinho e de Aristóteles, na primeira parte de sua principal obra para materializar sua hipótese. Em suas palavras:

É chegado o momento de ligar os dois estudos independentes que precedem e de por à prova minha hipótese de base, a saber, que existe entre a atividade de narrar uma história e o caráter temporal da experiência humana uma correlação que não é puramente acidental, mas que apresenta uma forma de necessidade transcultural. $\mathrm{Ou}$, em outras palavras: que o tempo torna-se tempo humano na medida em que é articulado de modo narrativo, e que a narrativa atinge seu pleno significado quando se torna uma condição da existência temporal (RICOEUR, 1994, p.85)

Sua tese central é a de que seria pela linguagem (com ato de intenção/distensão) que se resolveriam as aporias agostinianas e as contribuições aristotélicas. Pela reciprocidade e temporalidade, num terceiro tempo, que o tempo da narrativa. Assim, no lugar do tríplice presente agostiniano, Ricoeur propõe a noção de tríplice mimese, numa 
relação dialética e viva entre a prefiguração (ou mimese I); a configuração (mimese II) e a reconfiguração (mimese III). Segundo o autor:

O desafio é pois o processo concreto pelo qual a configuração textual faz a mediação entre a prefiguração do campo prático e sua reconfiguração pela recepção da obra. Aparecerá corolariamente, no termo da análise, que o texto é o operador por excelência que assume, por seu fazer - a ação de ler - a unidade do percurso de mimese I a mimese III através da mimese II. (RICOEUR, 1994, p.86-87)

Ressaltando que é através da mimese II que a mediação entre a apropriação do mundo e a sua reconfiguração acontece.

Já destacamos que a noção de tríplice mimese, na reflexão de Ricoeur, para nós, é mais apropriada do que a de tríplice presente de Santo Agostinho. Concentremos, então, um pouco mais de atenção sobre a mimese I. Nos termos aqui colocados, qualificando a mimese I, Ricoeur argumenta que, "a narrativa não se limita a fazer uso de nossa familiaridade com a trama conceitual da ação. Acrescenta a estas os traços discursivos que a distinguem de uma simples sequência de frases de ação" (RICOEUR, 1994, p. 90).

É bem verdade que tais traços discursivos são reveladores de um jogo dialético entre aquilo que assumimos que seja a verdade (ainda que ela seja verossímil) e o que pretendemos empreender no mundo. Esse, afinal, é o círculo hermenêutico de que fala o autor:

[...] a relação dupla entre regras de tessitura da intriga e termos de ação constitui, ao mesmo tempo, uma relação de pressuposição e uma relação de transformação. Compreender uma história é compreender ao mesmo tempo a linguagem do 'fazer' e a tradição cultural da qual procede a tipologia das intrigas. (RICOEUR, 1994, p. 91).

No entanto, tais narrativas são elaboradas dentro de um conjunto de regras, de convenções, que estabelecem alguns limites à atividade de tecer intrigas. Ou seja, se por um lado temos uma atividade altamente produtora/criativa, por outro temos um controle (uma regulação) dos mecanismos que, em larga medida, condicionam tal atividade. Vemos então, uma vez mais, o jogo dialético entre a imaginação produtora e a imaginação regrada, onde, se "a ação pode ser narrada, é porque ela já está articulada em signos, regras, normas: é, desde sempre, simbolicamente mediatizada" (RICOEUR, op.cit., p.91). 


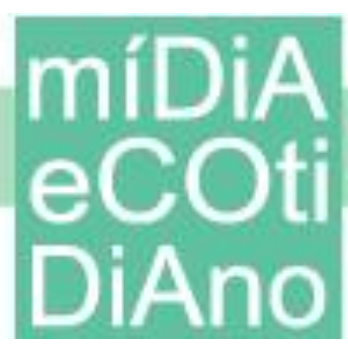

Evidentemente que a mediação simbólica é central no estabelecimento de uma compreensão mais ou menos comum entre os participantes de uma dada formação social. Quando Ricoeur aborda a questão do sistema simbólico, como aquele com capacidade de compartilhamento de significados, ele revela também o quanto tal sistema é objeto de normatização. Nas palavras do autor: "o termo símbolo introduz também a ideia de regra, não somente no sentido, que se acaba de dizer, de regras de descrição e de interpretação para ações singulares, mas no sentido de norma" (Ibid., p.93). Sua proposta é evidenciar o caráter ativo da elaboração da obra no mundo, de um fazer que dá unidade entre a prefiguração e a refiguração, através da configuração (mediação).

Em nossa avaliação, é justamente na mimese II (que possui a função de mediação) que acontece a aproximação com a construção da identidade dos sujeitos sociais. Isso se torna possível à medida que o passado é evocado e, por uma ação produtora, vai retornar ao mundo, refigurando-o. Nesse sentido, a tessitura da intriga seria o meio pelo qual qualquer ator social recebe as ressonâncias do mundo, configura-as e produzem leituras, que também retornaram ao mundo. Não é menos verdadeiro, no entanto, que o passado (ou o passado evocado no presente) tem que possuir um caráter de verossímil para que um determinado episódio seja compreensível. É aqui que o papel da articulação da memória (e, consequentemente, do esquecido) é central. Como, para nós, essa memória evocada recebe um investimento dos projetos que a sociedade abraça, é interessante pensarmos o quanto as respostas (ou atos de configuração) não são mais ou menos semelhantes, do ponto de vista da ação individual.

Quando nos detemos sobre a mimese III (a configuração), inevitavelmente somos instados a pensar o quanto, na contemporaneidade, esse mundo não está cada vez mais unificado pela ação dos media. Se esse questionamento é coerente, julgamos que as propostas teóricas do autor podem ser estendidas ao jornalismo à medida que este também trabalha na interface entre história e ficção. Como defende Ricoeur (Ibid., p.125):

É essa inspiração recíproca que me autoriza a colocar o problema da referência cruzada entre a historiografia e a narrativa de ficção. $\mathrm{O}$ problema só poderia ser escamoteado numa concepção positivista da história, que negligenciasse a participação da ficção na referência por traços, e numa concepção anti-referencial da literatura, que negligenciaria o alcance da referência metafórica em qualquer poesia. 
Em nossa avaliação, o problema (pelo menos no caso brasileiro) tem sido encoberto por uma ação positivista ${ }^{5}$ dos órgãos de imprensa nas narrativas que produzem. Um dos efeitos mais perniciosos desse processo é o fato de as narrativas produzidas pelos meios de comunicação receberem a chancela de verdadeiras, como se de fato não fossem discursos produzidos a partir de interesses claramente ideológicos. Nesse sentido, numa articulação com a contribuição teórica de Ricoeur, Barbosa (2006) destaca que:

[...] nas narrativas cotidianas dos meios de comunicação, e particularmente nos atos jornalísticos, observamos o quanto a questão da peripécia é fundamental para instaurar o acontecimento jornalístico. Baseado em convenções de veracidade, o discurso jornalístico é acreditado como verídico por antecipação. (BARBOSA, 2006, p. 141)

Movimento que acaba por conferir aos órgãos de imprensa o lugar especial de mediadores entre o acontecimento e a história.

Pelo que até aqui foi exposto, fica evidente a importância da memória dentro do processo de construção na problemática trabalhada por Ricoeur. O que não se pode perder de vista é que a memória é uma operação do presente, que assume parte do passado (construído e rememorado a partir do presente). Evidentemente que se trata de um processo complexo entre lembrar e esquecer, com disputa pelos recursos utilizados para que se rememore.

Como o foco do nosso interesse é a revista Radis (em contraposição aos meios de comunicação tradicionais), não podemos desprezar o tipo de memória que se produz, tampouco o quanto transformam seus documentos em monumentos, associado ao fato de se investirem de autoridade para apontar e destacar o que deve e como deve ser lembrado. A própria abordagem de Ricoeur, que propõe o deslocamento da questão "o que é memória?" para “do que se lembrar?” e, "por que se lembrar?”, evidencia o caráter seletivo da memória. Ao nos lembrarmos de algo no presente, não devemos perder de vista a necessidade de nos esquecermos de outras tantas lembranças. No entanto, também

\footnotetext{
${ }^{5}$ Estamos nomeando como positivista certa concepção de imprensa que descreve (narra) os fatos de uma maneira distanciada, escudada em pressupostos que são tomados "por empréstimo" das chamadas ciências positivistas, como a objetividade, a neutralidade, a imparcialidade na descrição do objeto investigado.
} 
não podemos negligenciar o quanto a memória se articula à identidade. Identidade essa que é produzida a partir de um jogo dialético e processual originado de situações, posições, interações.

Ao articularmos a memória e a identidade, queremos evidenciar o quanto a ação de evocar e posteriormente a de projetar está relacionada com a imagem que o sujeito quer manter de si. Essa perspectiva abre a discussão sobre a oposição memória individual versus memória coletiva, sendo esta fruto da interação ou do contraste do indivíduo com a sociedade (HALBWACHS, 1990) e aquela uma ação dependente puramente da vontade de cada um (BERGSON, 1999). Não vamos aqui nos aprofundar nesta questão. O que queremos é destacar, sobretudo a partir de Maurice Halbwachs, o quanto a memória é uma operação social, ainda que individualmente o sujeito organize suas lembranças (e as narrativas produzidas a partir destas lembranças) tomando por referência o tipo de projeto de vida que possua. Ainda que não recuperemos o debate entre Halbwachs e Bérgson, sobre se a memória é individual ou coletiva, concordamos com o primeiro, para quem a memória é individual na perspectiva de que o sujeito, ao lembrar, ocupa um determinado lugar na sociedade.

O que queremos enfatizar é a aproximação entre os argumentos de Halbwachs e Ricoeur quando aquele se interroga e, posteriormente argumenta sobre o que:

[...] seria desse 'eu', senão fizesse parte de uma 'comunidade afetiva', de um 'meio efervescente', do qual tenta se afetar no momento em que ele se recorda? [...] A rememoração pessoal situa-se na encruzilhada das malhas de solidariedade múltiplas dentro das quais estamos engajados e que traduzimos em uma linguagem. (HALBWACHS, 1990, p.14)

Evidentemente que, tanto em Halbwachs quanto em Ricoeur, a ação individual nem é livre de amarras. Trata-se antes de um jogo dialético entre o que poderíamos chamar de memória dominante versus memória do dominado. No entanto, o peso dado pelo sociólogo a correntes de pensamentos evidencia que as ações são mais ou menos sugeridas a quem as executa.

Nos termos aqui expostos, é igualmente interessante observarmos que vai se tornando mais ou menos evidente que o passado é interpretado (ou reinterpretado) de acordo com a nossa visão presente (ou posição no presente). Ou seja, damos sentido ao 
passado no presente. Nessa complexa trama também parece difícil negar que, contemporaneamente, os meios de comunicação de massa têm dado uma ajuda considerável nesse processo. No entanto, a relação tempo/espaço é central nesse esforço memorável. Em Halbwachs vemos, por exemplo, a distinção entre rememorar e reconstruir (ou lembrar e imaginar, como propõe Ricoeur), onde esta apareceria no lugar em que a relação presente versus ausente é mais distante; e aquela, quando a relação é mais próxima. Dessa forma, a memória é o passado contido no presente e o passado histórico, como argumenta Heller (1993), "não é o que é esquecido, mas aquilo que pode ser relembrado. Neste sentido, o passado está, na verdade, exclusivamente contido no presente. Entretanto, só é possível relembrar-se daquilo que foi esquecido" (HELLER, 1993, p. 107).

\section{RADIS: um relevante ator social da memória da saúde brasileira}

A revista Radis faz parte do Programa Radis de Comunicação e Saúde - um programa nacional e permanente da Escola Nacional de Saúde Pública (ENSP), da Fundação Oswaldo Cruz (Fiocruz), iniciado em 1982 - que tem nas iniciais do nome os objetivos do projeto original: Reunião, Análise e Difusão de Informação sobre Saúde. Desde 2002, ano em que a primeira edição da revista Radis ${ }^{6}$ circulou, o Programa Radis reuniu todo seu acervo em mídia digital, incluindo as publicações anteriores à revista (Súmula e Tema - até 2002; Dados - até 1996; e Proposta - O Jornal da Reforma Sanitária - entre 1986 e 1993, renomeado Jornal do Radis - em 1994), permitindo ao leitor ter acesso (rememorando) e fazer buscas no acervo digital. No mesmo ano, foi lançada a revista Radis, incorporando algumas características das publicações anteriores, com periodicidade mensal e maior volume de conteúdo ${ }^{7}$.

Além de significativo ator social da memória da saúde brasileira, o Programa Radis também pode ser considerado um relevante ator político, que produziu e que produz diversos discursos sobre o SUS e sobre a saúde pública do Brasil ao longo dos 30 anos

6 A primeira edição é datada de agosto de 2002. Disponível em: https://radis.ensp.fiocruz.br/phocadownload/revista/Radis01_web.pdf 7 Idem. 
do Sistema Único de Saúde. Por esse motivo, decidimos tomar a Revista Radis como objeto de investigação, compreendendo que a Radis ajuda a dar forma a essa memória e entra num processo de disputa pela memória do SUS com a chamada imprensa comercial tradicional.

Com essa perspectiva, cabe também localizarmos a revista Radis no tempo e no espaço. Produzida por profissionais da comunicação, a revista está dentro de uma instituição pública de saúde, a Fundação Oswaldo Cruz (Fiocruz), que é subordinada ao Ministério da Saúde. A Fiocruz, por sua vez, reúne em seu corpo de profissionais, inclusive, um grande número de médicos e profissionais da saúde pública que fizeram parte do Movimento da Reforma Sanitária Brasileira ${ }^{8}$. Alguns dos profissionais que trabalham (ou trabalharam) na Radis acompanharam de perto a criação do Sistema Único de Saúde, em 1988.

A revista, que tem em média 36 páginas, é enviada, gratuitamente, para mais de 100 mil assinantes em todos os municípios do país e seu cadastro abrange: todos os conselhos e secretarias municipais e estaduais de Saúde do Brasil, prefeituras, câmaras municipais, assembleias legislativas e os parlamentares do Congresso Nacional, organizações não governamentais, órgãos da mídia, entidades sindicais e de moradores, bibliotecas, escolas, estudantes e profissionais de todos os níveis das áreas da saúde e afins ${ }^{9}$. Um dos lemas da revista é a busca e a defesa por uma saúde pública de qualidade, assim como o desejo por uma comunicação em defesa da saúde e da democracia, ratificando seu alinhamento com os princípios do SUS.

Podemos afirmar, mesmo antes de apontarmos outros elementos que sustentem nossa análise, que os sentidos e a memória produzidos sobre a saúde pública pelas publicações do Projeto Radis são muito diversos daqueles mobilizados pelas revistas e jornais comerciais brasileiros. Logo, sua entrada no jogo da memória efetiva-se por um projeto que tem no SUS as bases de sua ação. Com isso, certamente cada um aciona lógicas e procedimentos próprios aos seus universos de interesse e de construção

\footnotetext{
${ }^{8}$ Para maior compreensão do Movimento da Reforma Sanitária Brasileira há uma ampla bibliografia disponível, entre eles podemos citar: AROUCA (1987); TEIXEIRA (1988); ESCOREL (2012); PAIM (2005); entre outros.

9 Disponível em: https://radis.ensp.fiocruz.br/index.php/programa-radis
} 
identitária. Nesse sentido, nos interessa entender as dinâmicas específicas desses discursos, que se fazem num jogo entre lembrar e esquecer, a partir daquele processo descrito por Ricoeur operado pela mediação que a mimese II faz entre a mimese I e a mimese III.

Numa observação rápida em jornais e concomitantemente na Radis, poderíamos destacar que a memória produzida pela grande mídia comercial é pouco (ou nada) comprometida com um senso de defesa dos serviços públicos do país, em especial no que diz respeito à saúde pública brasileira, haja vista os muitos compromissos assumidos com anunciantes - muitos deles representantes do chamado complexo industrial-farmacêutico. Em contraposição, é possível notar em Radis, especialmente pelos compromissos públicos que assume, uma clara defesa de uma saúde equânime, integral e universal. Recorrentemente a revista destaca a saúde como um direito garantido na Constituição, tornando latente ao seu leitor a importância de se de lutar por este e outros direitos igualmente constitucionais.

A grande mídia comercial brasileira, até mesmo por suas características específicas, tem uma abordagem em relação à questão da saúde pública bastante diferente. Nas memórias e nos esquecimentos que vão sendo produzidos ao longo do tempo, através de narrativas que refletem a maneira como se sugere que a população se relacione com o SUS, é possível observar, conforme destaca Machado (2014, p. 237), a partir de análises de narrativas jornalísticas sobre o Sistema Único de Saúde em diálogo com pesquisa realizada pelo Instituto de Pesquisa Econômica e Aplicada (IPEA, 2011) ${ }^{10}$, que os meios de comunicação interferem diretamente na construção e na transformação da realidade da população, além de influenciarem na percepção que cada indivíduo tem da realidade.

De acordo com Ipea (2011, p.4), a percepção da população sobre o SUS é mediada por inúmeros fatores, que vão desde a própria experiência na utilização dos serviços, à experiência de outros membros da família ou da comunidade, dentre outros fatores, como por exemplo, “aquilo que é divulgado pelos meios de comunicação interfere na formação

\footnotetext{
${ }^{10}$ Em fevereiro de 2011, o IPEA divulgou os resultados do Sistema de Indicadores de Percepção Social (SIPS) com o tema "Saúde" onde buscou avaliar a percepção da população sobre os serviços prestados pelo SUS. A pesquisa coletou dados no período de 3 a 19 de novembro de 2010, nos domicílios dos 2.773 entrevistados, em todas as unidades da federação.
} 
de uma opinião geral". Nesses termos, concordamos com o historiador Henry Rousso (2016, p.57), quando este afirma que: "A ausência da memória pode se transformar rapidamente num caso sobre forma de esquecimento verídico."

Destacaríamos ainda que, ao analisar a revista Radis, é possível notar que não há uma defesa acrítica do sistema público de saúde. Críticas são apresentadas, assim como as ineficiências, os insucessos e os gargalos do SUS são debatidos e relatados, com a colaboração de gestores, profissionais e usuários. Regularmente é possível identificar, igualmente, uma variedade de fontes e vozes sendo convocadas para ilustrar as publicações, com seus relatos e visões acerca da saúde pública. De acordo com a própria revista, "a Ensp e a Fiocruz entendem que é dever do Estado assegurar que todo brasileiro tenha o direito a ter acesso a informações claras, precisas e qualificadas em Saúde e, principalmente, a ter sua voz ouvida" ${ }^{11}$.

Assim como nos jornais diários, de caráter comercial, os pressupostos do jornalismo, como seleção de fontes variadas, busca por debates da atualidade, divulgação de eventos, uso de testemunhos, espaço para o leitor se pronunciar, regularidade em sua publicação (periodicidade) etc., conferem à revista a legitimidade de um produto jornalístico como muitos outros que estão em circulação. É tal identificação do fazer jornalístico de Radis que nos autoriza o tomá-la como um ator que também efetiva a tessitura da intriga a partir dos caracteres da narrativa e ação jornalísticas, recebendo as ressonâncias do mundo, refigurando-as e devolvendo-as ao mundo.

Se do ponto de vista de quem produz memória o papel da Radis já é inferido, sua identificação como espaço repositório da memória da saúde pública do país parece validar nossa premissa de que, seu lugar como ator social relevante da memória da saúde brasileira, configura igualmente o lugar de ator político, especialmente ao anunciar que mantém atividades de documentação relacionada ao acervo de publicações e se autodeclara como "detentores de uma hemeroteca com perfil único do país". A hemeroteca reúne mais de 245 mil recortes sobre saúde e seu conceito ampliado. ${ }^{12}$

11 Disponível em: https://radis.ensp.fiocruz.br/index.php/programa-radis.

12 Idem. 


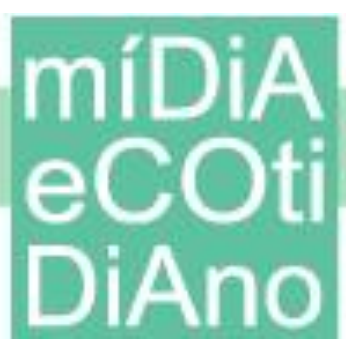

Além disso, na página do Programa Radis, na internet ${ }^{13}$, é possível ter acesso, através de um sistema de busca, a praticamente todo conteúdo das revistas. Todas as edições da revista Radis - de agosto de 2002 até os dias atuais (até o mês de abril de 2019, somam um total de 199 edições) estão disponíveis na íntegra, para consulta e download, não sendo necessário nenhum tipo de cadastro no site.

Em sua edição de julho de 2017 (n. ${ }^{\circ}$ 178), ${ }^{14}$ quando o Programa Radis completou seus 35 anos, a revista anunciou em seu editorial, que quatro mil, das quase $60 \mathrm{mil}$ fotografias do acervo do programa, que resultaram de reportagens do Programa Radis desde a década de 1980, a partir daquele momento, estavam disponíveis para consulta na plataforma flirck e poderiam ser baixadas para uso não comercial. Em nossa avaliação, esse movimento sublinharia, uma vez mais, o movimento da revista (e do Programa) de entrar na luta por produzir memórias e colaborar na construção da história da saúde pública. Para além deste acervo de fotografias das reportagens, no site da revista é possível identificar também um link chamado "imagens", onde se pode ter acesso a diversas fotos de coberturas de eventos feitas pelas equipes do periódico.

Do ponto de vista do interesse em manter viva a memória da saúde pública, através da revista, e permitir aos usuários acessos on line, o que Radis realiza é um trabalho que transcende a disposição de manutenção da história da publicação. Em nossa avaliação, o que a publicação realiza é exatamente aquele trabalho ativo e criativo da memória, nos termos propostos por Ricoeur. Na verdade, o movimento de manter viva certa perspectiva da história da saúde pública do país, pode ser sustentando pelo trabalho de trazer notícias de temas da atualidade, negociando com o passado e refigurando temas históricos do campo da saúde.

\section{Parte do passado da saúde pública brasileira atualizado por Radis}

Do ponto de vista da exploração do corpus, apresentamos a seguir alguns exemplos de como a saúde pública é rememorada pela revista. É importante destacar que não se trata aqui de recuperar uma cronologia dos últimos trinta anos. Antes, interessa-

\footnotetext{
${ }^{13}$ https://radis.ensp.fiocruz.br/index.php/revista/todas-edicoes

${ }^{14}$ https://radis.ensp.fiocruz.br/phocadownload/revista/Radis178_web.pdf/ . Acesso em 20/01/2019.
} 
nos iluminar como o passado aparece atualizado no presente a partir da forma como Radis organiza sua narrativa. Com essa perspectiva, selecionamos algumas capas, seguidas de algumas páginas internas do periódico. Aqui não pretendemos apresentar nenhuma análise aprofundada. Nosso olhar se voltou inicialmente para capas (posteriormente para o interior da revista) cujas imagens ou títulos nos remetiam a fatos que nos levavam a eventos do passado da saúde - que podem reforçar o interesse da revista em colaborar para a produção de memórias sobre a saúde pública. É possível observar que, para contar fatos históricos ou comemorar eventos/datas com regularidade, são mostrados infográficos ou imagens. A história de determinados eventos, doença ou personalidade são recorrentemente apresentadas a partir de uma linha do tempo. O uso de palavras como "memória", "história", "tempo" e "cronologia" são também marcadores importantes a serem observados. Vejamos alguns exemplos a seguir:

1) Radis $\mathrm{n}^{\mathrm{o}} 10^{15}$ - Junho de 2003 - Capa +páginas:11 e 12:

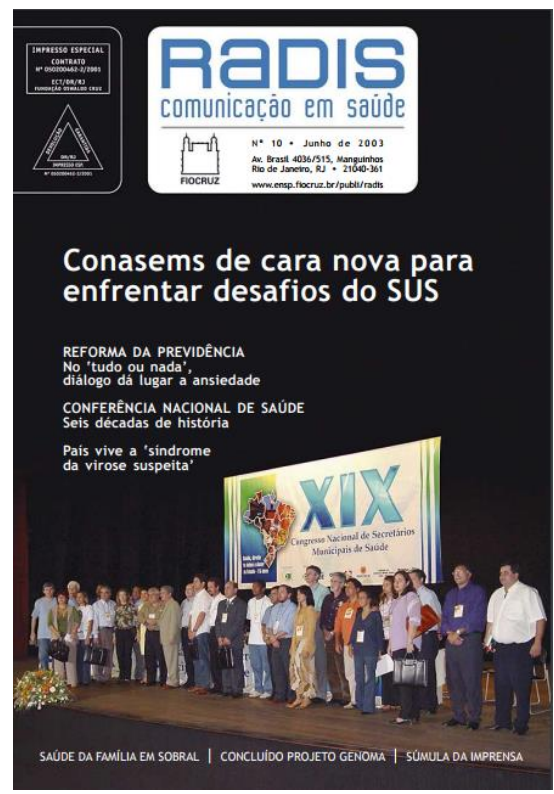

${ }^{15}$ Disponível em: https://radis.ensp.fiocruz.br/index.php/todas-as-edicoes/10 . Acesso em 20/01/2019. 


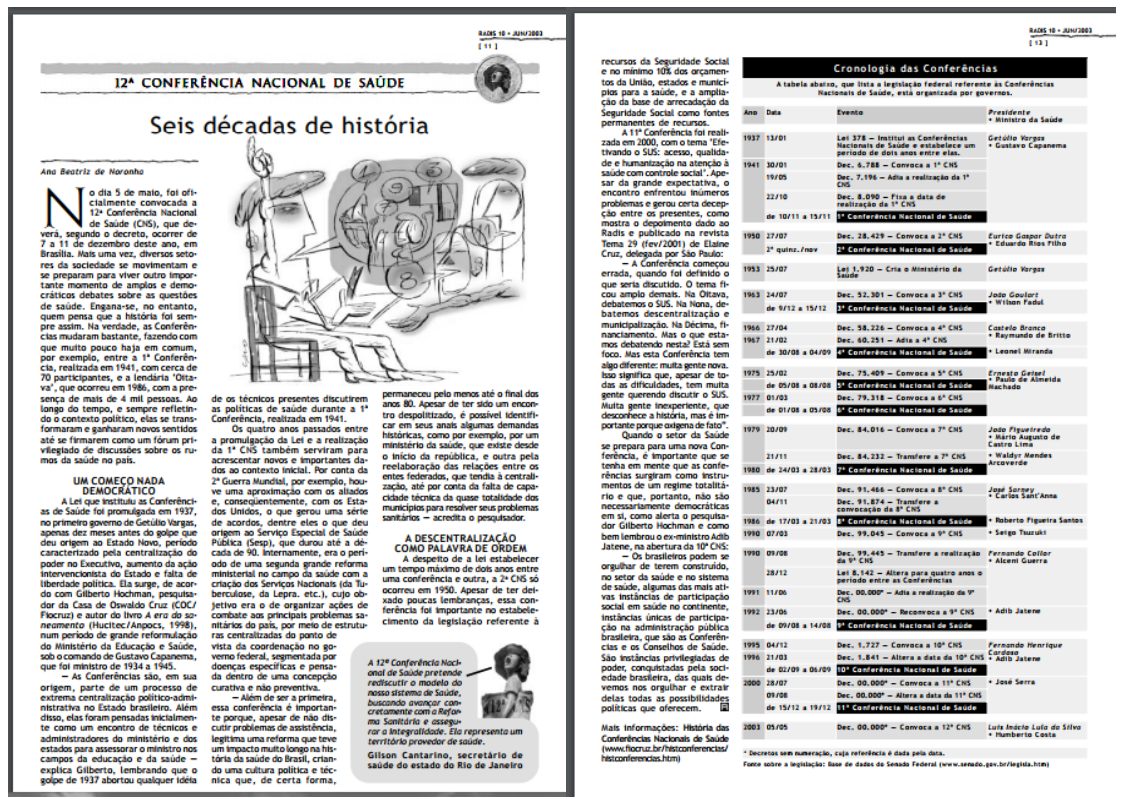

É visível uma forma de construir um entendimento da história da saúde a partir de uma cronologia linear. Como se pode observar na última imagem, dentre estas páginas acima, apresenta-se um quadro cujo título é: Cronologia das Conferências e a partir daí um pouco da história das conferências de saúde é mostrada. É evidente que há uma seleção sobre o que vai ou não ser utilizado para o preenchimento deste quadro e esse recurso da seletividade dos fatos e personagens não faz parte apenas das práticas jornalísticas, mas de qualquer discurso e, por isso, de qualquer prática mnemônica (que produz memórias individuais ou coletivas). Por isso, a seletividade no uso das palavras e expressões também são elementos importantes a serem observados nos meios de comunicação. Afinal, se admitimos a perspectiva de que as palavras podem ser usadas como formas de poder e dominação, não se pode ignorar todos os elementos constitutivos do discurso.

2) Radis $n^{\circ} .40^{16}$ - Dezembro de 2005 - Capa + páginas: 10, 15 e 16:

\footnotetext{
${ }^{16}$ Disponível em: https://radis.ensp.fiocruz.br/index.php/todas-as-edicoes/40 . Acesso em 20/01/2019.
} 

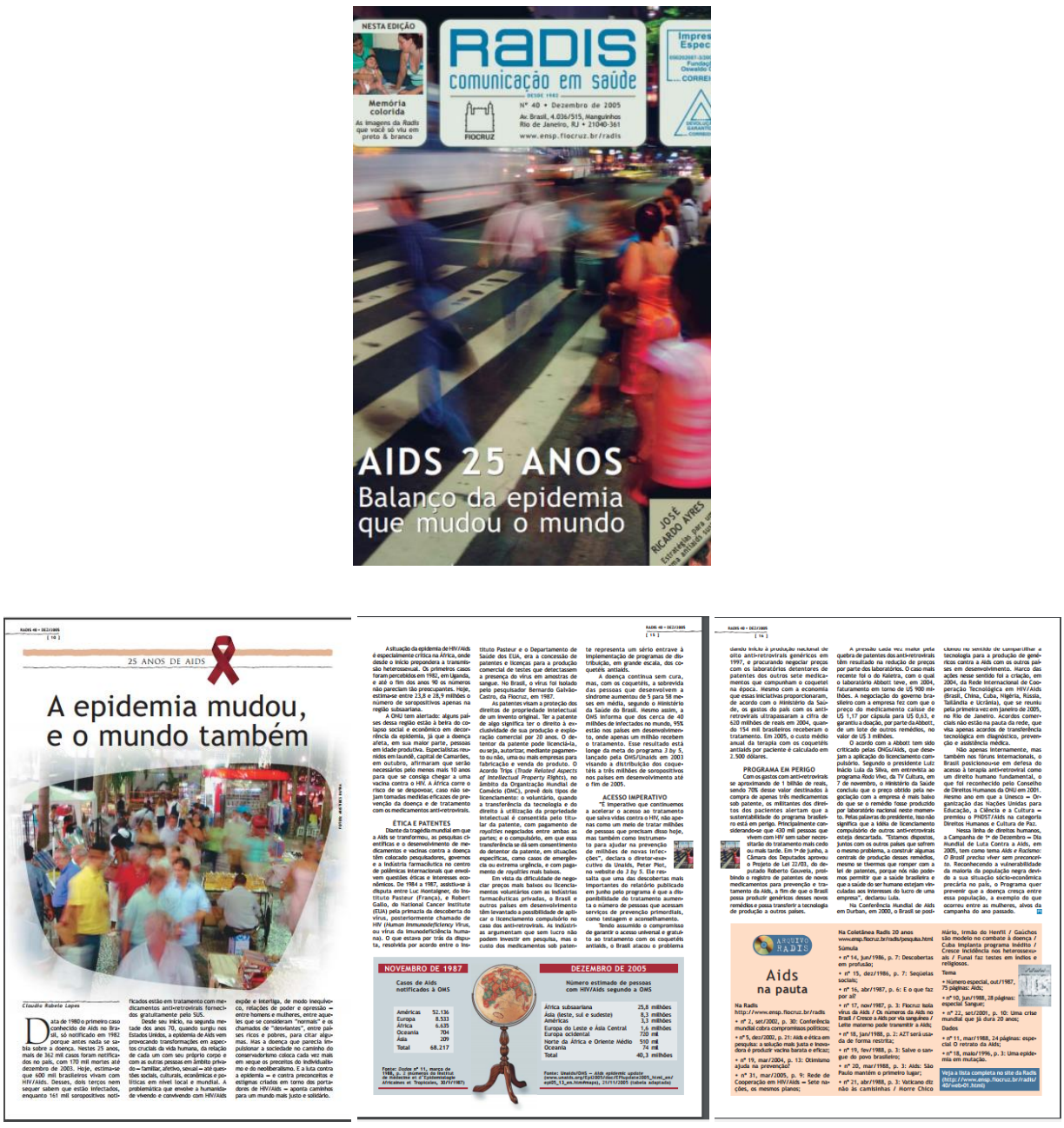

Mostrar a contagem do tempo, o que mudou ou não no mundo, apresentar elementos com marcadores temporais explícitos nos calendários, nos revelam novamente uma perspectiva de inserção num tempo e espaço que são tão caros nos estudos de história e memória. Nas páginas apresentadas anteriormente (Radis $\mathrm{n}^{\circ} 40$ ) é possível identificar não apenas esses elementos, como também é possível observar um box com o título: "Aids em pauta", que está sob o selo "Arquivo Radis". A revista apresenta ali uma lista com diversos textos que já foram publicados pelo Programa Radis ao longo dos últimos anos e fornece ao leitor data e link para que mesmo possa acessá-lo. Deste modo, a revista facilita e adianta parte de uma pesquisa em seu arquivo, possibilitando que, qualquer pessoa que esteja interessada no tema, possa não apenas conferir o material produzido pelo programa, mas identificar as demarcações deixadas e a responsabilidade e interesse 


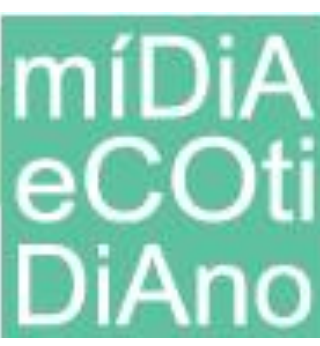

em tratar regularmente um tema tão importante na área da saúde pública, como é a temática Aids. Por outro lado, a revista também expressa, através desse expediente, um desejo de controle do percurso no acervo (na memória material) da revista e de disputar a memória da saúde pública brasileira.

3) Radis $n^{\circ} 60^{17}$ - Agosto de 2007: Capa + páginas: 19, 31 e 32.
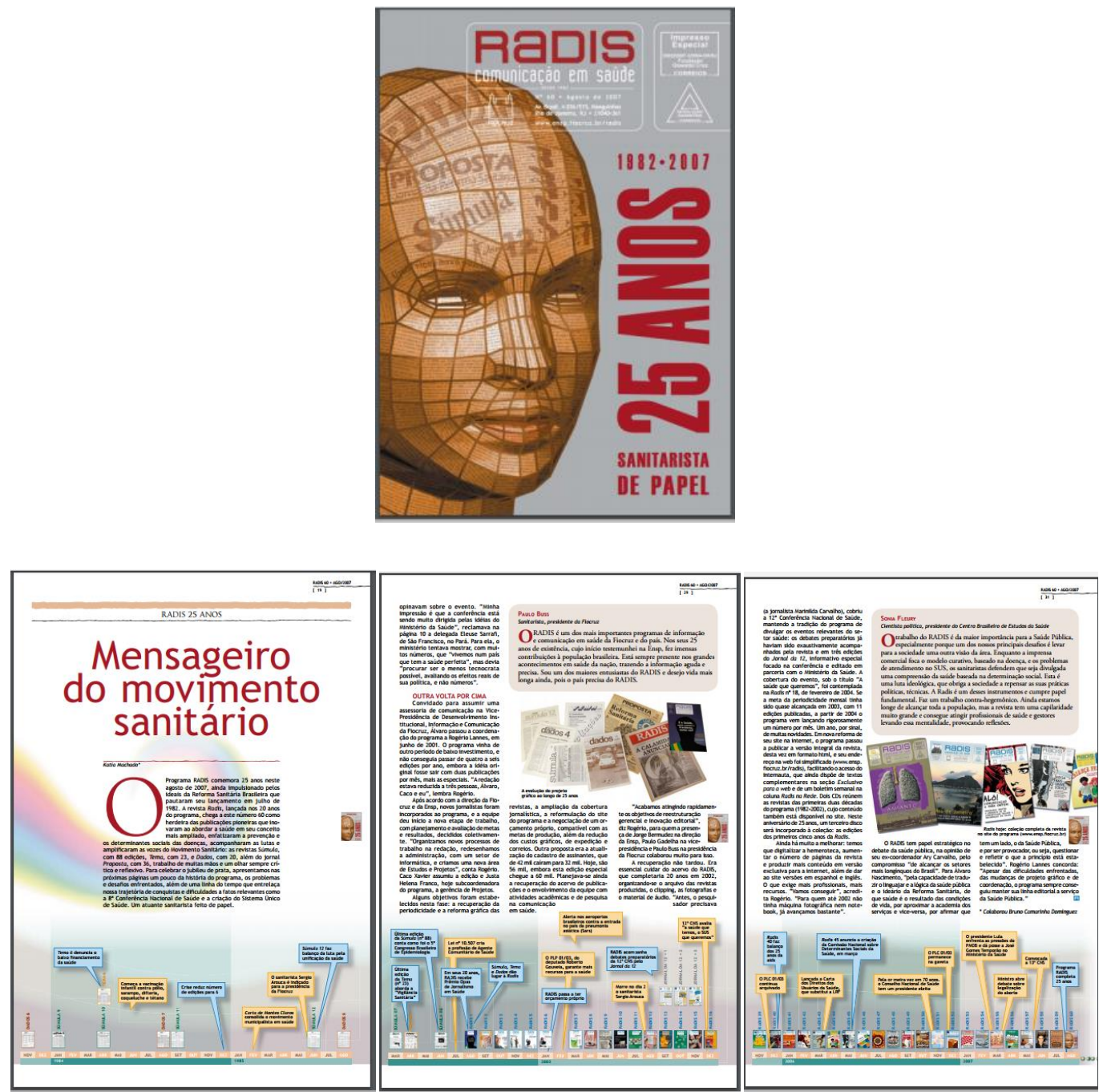

Quando o Programa Radis completou seus 25 anos de existência, a revista Radis (edição de Agosto de 2007) apresentou uma linha do tempo do Programa Radis e seu entrelaçamento com as questões que fazem parte da história da saúde pública brasileira.

${ }^{17}$ Disponível em: https://radis.ensp.fiocruz.br/index.php/todas-as-edicoes/89 . Acesso em 20/01/2019. 


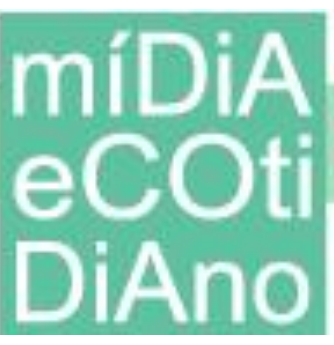

PPGMC

uff

A reportagem no interior da revista ocupa 16 das 36 páginas desta edição. A apresentação de uma linha do tempo é marca forte nas publicações da Radis, como já mencionamos. Ao se auto-declarar na capa da revista "25 Anos Sanitarista de Papel" e "Mensageiro do Movimento Sanitário", o Programa Radis faz questão de se assumir como ator político ativo no processo da Reforma Sanitária brasileira. Assumindo-se também como uma espécie de guardião da memória da saúde pública, o programa demarca seu lugar como ator político-social ativo da história e se coloca como produto importante no jornalismo sobre saúde do país.

4) Radis $n^{o} 72^{18}$ - Agosto de 2008 - Capa + páginas: 10, 12, 13 e 16:
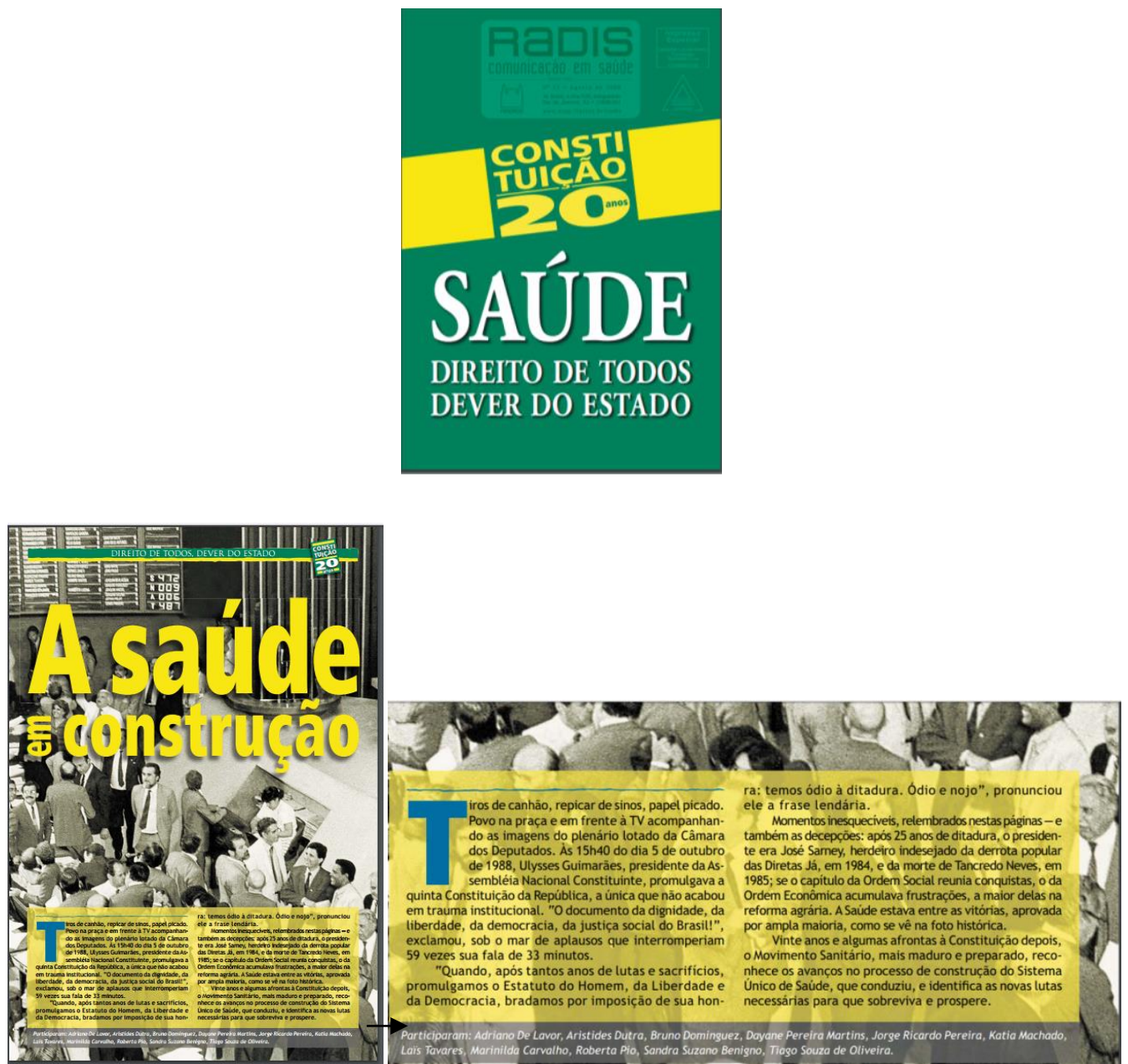

\footnotetext{
${ }^{14}$ Disponível em: https://radis.ensp.fiocruz.br/phocadownload/revista/Radis72_web.pdf . Acesso em
} 20/01/2019. 


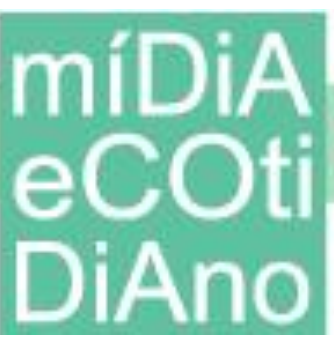

A reportagem que está no interior da revista (que tem início na pág.10), ocupa 24, das 36 páginas desta edição. Traz elementos do passado que vão desde usos de recortes de jornais, fotografias de arquivo, texto da Constituição Federal de 1988, como também faz um apanhado histórico de como se deu os movimentos e atos políticos na saúde detalhando o contexto político e social da década de 1980, quando ocorreu a mais emblemática Conferência Nacional de Saúde - a $8^{\text {a }}$ Conferência, em 1986 - combinando vários elementos do passado com o momento atual da publicação. Além disso, faz uso de palavras/expressão como "Documento Histórico", "Pungente saudade", "frases lendárias", "momentos inesquecíveis", entre outras.
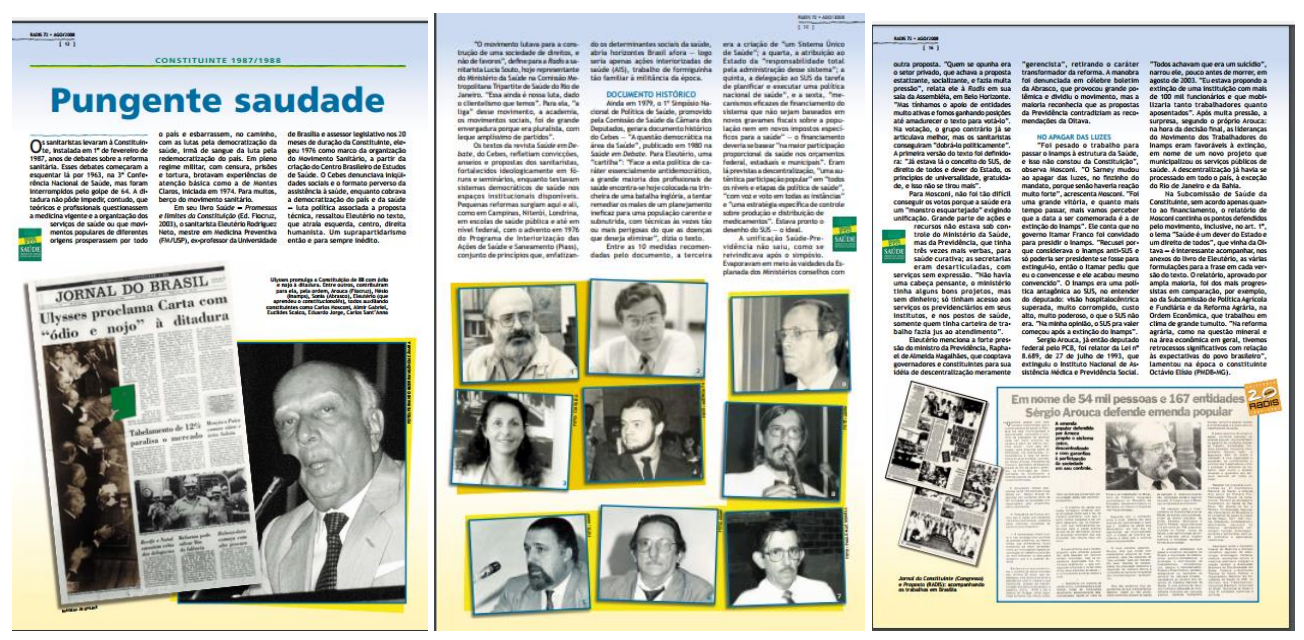

Trata-se de uma edição notoriamente dedicada a atualizar na memória coletiva a década de 1980, o momento político que vivia o país e a situação em que se encontrava a saúde pública brasileira. A seguir, um pequeno trecho do que foi a apresentação desta edição da revista $\mathrm{n}^{\circ} 72$ :

Saudosismo, descrédito, realismo e esperança estão presentes nesta edição, cuja matéria de capa dividimos em três partes, para contar com pungente saudade a bela luta de duas décadas até inscrever-se o ideário da Reforma Sanitária na Constituição, analisar criticamente o nivelamento por baixo que tomou conta do Sistema Único de Saúde real e avaliar os desafios do projeto a concluir para que o sonho civilizatório e solidário da saúde para todos se realize. [...] (Editorial Radis, nº 72; p.3) 
Um passado nem tão distante e temos um interessante exemplo de como o próprio jornalismo buscar exercer muitas vezes o que é denominado "história do tempo presente". $\mathrm{Na}$ prática, ao fazer essa história do tempo presente, o pesquisador acaba sendo contemporâneo de seu objeto e, por isso, ele compartilha com aqueles que fazem a história, ou seja, os seus atores, as mesmas categorias e referências. Seguramente, parte do corpo de profissionais de Radis participou ativamente do movimento de redemocratização do Brasil e alguns certamente estiveram presentes em momentos marcantes para a saúde pública brasileira, como a $8^{\text {a }}$ Conferência Nacional de Saúde $(1986)^{19}$, a institucionalização do SUS na Constituição de 1988, Movimento da Reforma Sanitária, entre outros. Entretanto, aqui se iguala o movimento de portador de uma memória da saúde pública brasileira pela forma como tanto Radis como os jornais da imprensa tradicional deixam tais marcas implícitas.

5) Radis $\mathrm{n}^{\circ} 120^{20}$ - Agosto de 2012 - Capa + páginas: 8,12 e 13:

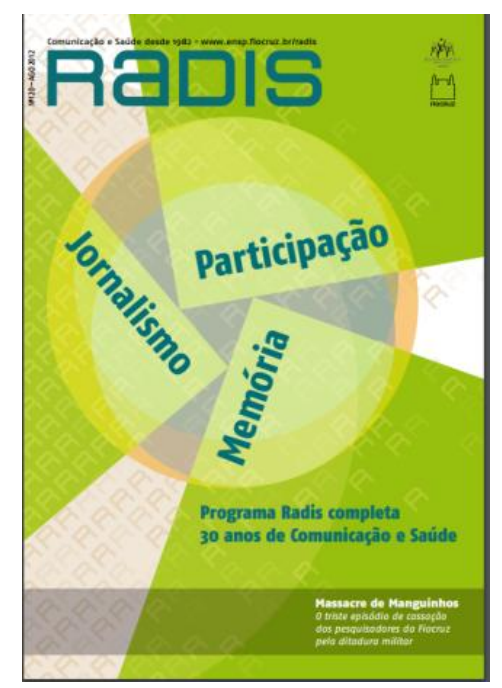

\footnotetext{
${ }^{19}$ De acordo com Escorel (2012), as conferências de saúde no Brasil têm origem em 1937 (lei n.378). Elas foram criadas com o principal objetivo de proporcionar a articulação do governo federal com os governos estaduais, dotando-o de informações para formulação de políticas e também para a concessão de auxílios e subsídios financeiros. Desde a sua criação as conferências sofreram grandes mudanças, mas todas de alguma maneira interferiram nas políticas de saúde. A VIII Conferência é considerada um marco e foi fundamental para o processo da reforma no sistema de saúde brasileiro. Teve ampla participação das organizações da sociedade civil de todo país, incluindo representações sindicais, associações de profissionais de saúde e movimentos populares em saúde.

20 Disponível em: https://radis.ensp.fiocruz.br/phocadownload/revista/Radis120_web.pdf. Acesso em 20/01/2019.
} 

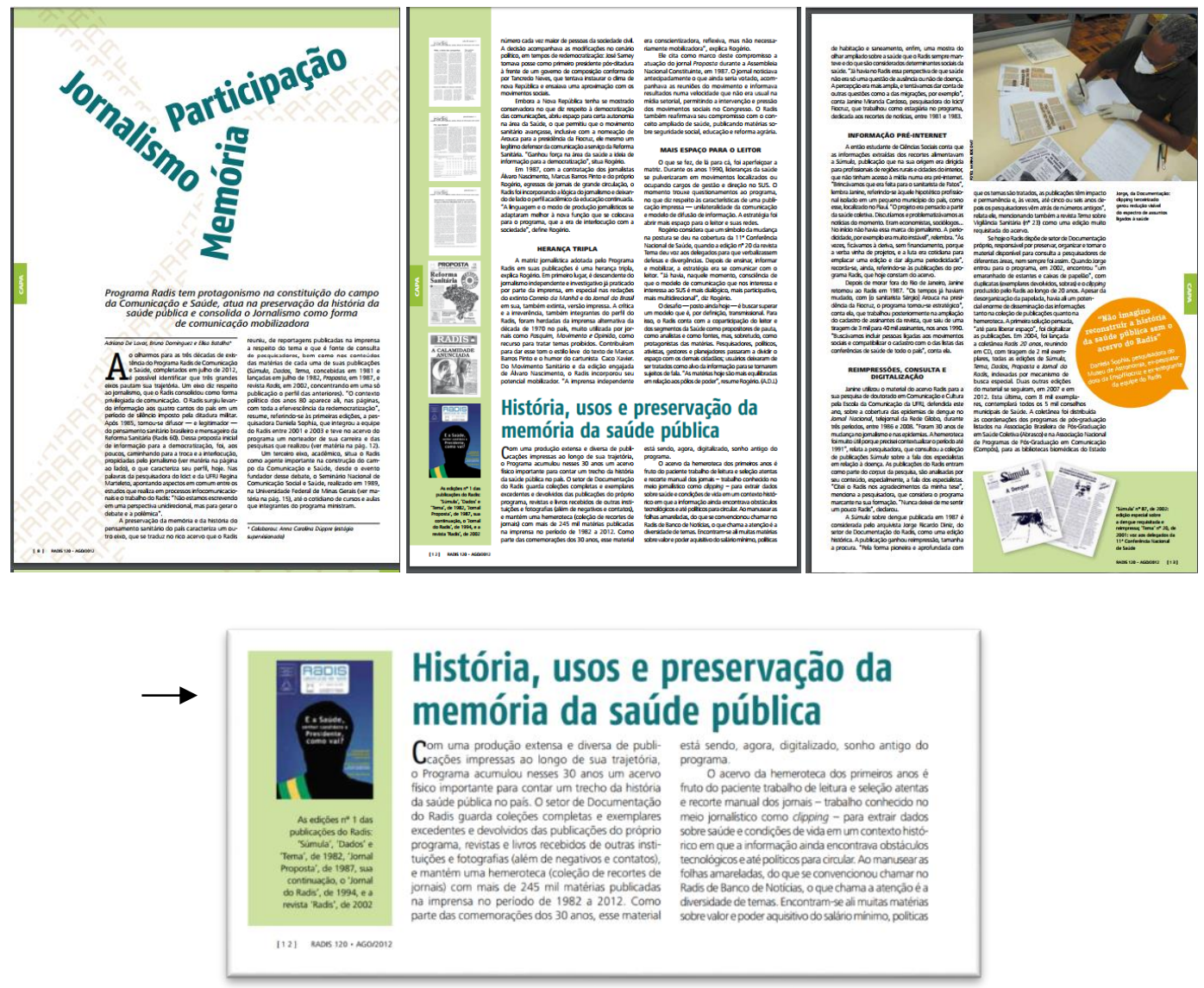

Nesta edição de Agosto de 2012, a revista Radis ressalta, mais uma vez, seu papel na história da saúde pública brasileira e deixa evidente seu interesse em preservar essa história. A reportagem de capa, que ocupada da página 08 até a página 10 da publicação, busca apresentar um passeio pela trajetória da Radis. A publicação, concomitantemente, assume-se como responsável pela construção e preservação da memória da saúde pública do país. Mostra-se, ao longo de todo texto sobre a comemoração dos seus 30 anos de existência, seu compromisso com o acervo construído pela publicação e com a memória que vem produzindo ao longo de três décadas, traz depoimentos de diversos colaboradores e profissionais que ao longo dessas três décadas produziram material para a revista e também traz declarações de leitores da revista.

A Radis, além de produzir notícias e reportagens no campo da saúde, também disponibiliza uma área reservada aos leitores - em que publica comentários de leitores e há uma área da revista denominada Súmula (fazendo referência à antiga publicação), 
onde traz textos e temas discutidos por diversos meios de comunicação, fornecendo o crédito a quem deu a publicação original e propondo algum breve debate sobre do assunto. A revista busca em datas passadas, em outros periódicos, temas anteriormente debatidos e, a partir destes textos localizados no passado, propõem uma rememoração. O leitor, que pode já ter lido o material em outros veículos de comunicação, é assim instado a reatualizar, no contexto presente, os sentidos que foram produzidos no passado.

Por ser um periódico que, segundo própria revista, chega "a ser lido por mais 100 mil pessoas e instituições e tendo ainda uma demanda de mais de mil pedidos de assinaturas" (Radis, $\mathrm{n}^{\circ} 178$, Editorial), é notório que se trata de um produto comunicacional de ampla circulação e com grande potencial de fomentar discussões que não ficam apenas nos debates da atualidade. Recorrentemente a revista procura dar destaque à eventos e decisões políticas considerados históricos no campo da saúde pública brasileira e reatualiza essas questões para os leitores. Dessa forma, a revista também constrói - através de um processo de autorreferenciação - sua própria identidade.

\section{Considerações Finais}

Essa iniciativa do Programa Radis em investir não apenas num acervo para sua própria consulta, mas colocando à disposição de todo cidadão, demonstra um interesse em não apenas democratizar o acesso e fomentar discussões no campo da saúde pública, mas também uma iniciativa de produzir uma memória que dialogue com os princípios de um Estado democrático de direito, garantindo informação e possibilitando a prática de ações que visem a democratizando a comunicação. Este é o lugar de fala - e também o lugar político - que a revista faz questão de demarcar para si. Considerando seu conteúdo, Radis estimula discussões para além da narrativa hegemônica proposta pela grande mídia comercial do país no que diz respeito a discussões acerca da saúde pública brasileira. Aliás, com certa regularidade, a revista dialoga com temas que estão sendo tratados pela grande mídia comercial, porém buscando abordagens diferenciadas.

Com periodicidade mensal, a revista não apenas cobre eventos da área da saúde, como também apresenta histórias de ações e programas de saúde pública nas diversas regiões do país, problematizando a discussão entre saúde pública e saúde privada, 


\section{míDiA

mantendo atualizadas as discussões sobre políticas públicas e conjunturas vigentes, estabelecendo recorrente diálogo entre serviços de saúde e usuários do SUS. Frequentemente, como vimos, a revista relembra também acontecimentos importantes da área da saúde - como conferências, datas definidas como de combate a determinadas patologias, entre outros - e busca reforçar os princípios balizadores do SUS, trabalhando questões de saúde e doença, levando em consideração o conceito ampliado de saúde e buscando historicizar tais questões.

Por fim, outra observação que caberia a respeito do periódico é que se dispõe a defender a regionalização do jornalismo - não fixando suas histórias apenas a grandes centros urbanos ou apenas a regiões com forte destaque político. Produz uma diversidade de narrativas em torno da saúde pública na maioria das vezes dando conta de contextualização e recuperando no passado elementos que dialoguem com questões da atualidade - especialmente nas grandes reportagens.

Nesses termos, nos sentimos autorizados a afirmar que Radis, além de um significativo ator político no campo sanitário, se configura também como um importante ator social na guarda e na atualização da memória da saúde pública brasileira, no geral, e do SUS, em particular.

\section{Referência Bibliográfica}

ARAÚJO, I. S. e CARDOSO, J. M. Comunicação e Saúde. Rio de Janeiro: Fiocruz, 2007.

AROUCA, A. S. da S. Democracia é saúde. In: CONFERÊNCIA NACIONAL DE SAÚDE, 8.,1986, Brasília. Anais. Brasília: Centro de Documentação do Ministério da Saúde, 1987. p. 35-42.

BARBOSA, M. O filósofo do sentido e a comunicação. IN: Conexão, v.5, n ${ }^{\circ}$. Caxias do Sul: UCS, 2006.

Memória: um passeio teórico. In: Percursos do olhar: comunicação, narrativa e memória. Niterói/Rio de Janeiro: Eduff/Mauad, 2007.

UFF, 2007, Mimeo.

Paul Ricoeur, o reino da tríplice mimese ou a tessitura da intriga. Niterói:

BERGSON, H. Matéria e Memória. Ensaio sobre a relação do corpo com o espírito. São Paulo: Martins fontes, 1999.

BORGES, W. C. Espaço Publidiático e hegemonia ideológica: construção narrativa atravessada pelo imaginário. IN: Passagens - Revista Internacional de História Política e Cultura Jurídica, v.02. Rio de Janeiro, 2010. 
A narratologia deve estar atenta à cultura. In: LERNER, K; SACRAMENTO, I. (Org.) Saúde e Jornalismo: interfaces contemporâneas. Rio de Janeiro: Editora Fiocruz, 2014.

ESCOREL, S. História das Políticas de Saúde no Brasil de 1964 a 1990: do golpe militar à Reforma Sanitária. In: Giovanella, L; Escorel, S.; Lobato, L.V.; Noronha, J.C.; Carvalho, A.I.. (Org.). Políticas e Sistema de Saúde no Brasil. 2ªed.Rio de Janeiro: Editora Fiocruz, 2012, v. 1, p. 323-364.

HALBWACHS, M. A memória coletiva. São Paulo: Vértice, 1990.

Les cadres sociaux de la mémoire. Paris: Mouton, 1925.

HELLER, A. Uma teoria da história. Rio de Janeiro: Brasiliense, 1993.

INSTITUTO DE PESQUISA ECONÔMICA APLICADA (IPEA). Secretaria de Assuntos Estratégicos da Presidência da República. Sistema de Indicadores de Percepção Social (SIPS) - SAÚDE. Brasília, 9 fev.2011. Disponível em: http://www.ipea.gov.br/portal/images/stories/PDFs/SIPS/110207_sipssaude.pdf. Acesso em $21 / 10 / 2014$.

MACHADO, I. B. Percepções sobre o SUS: o que a mídia mostra e o revelado em pesquisa. In.: Lerner, K; Sacramento, I. (Org.) Saúde e Jornalismo: interfaces contemporâneas. Rio de Janeiro, Editora Fiocruz, 235-250, 2014.

PAIM, J. S. O pensamento do movimento sanitário: impasses e contradições atuais no marco da relação público-privado no SUS. In: HEIMANN, L.S; IBANHEZ, L.C; BARBOZA, R. (Org.). O público e o privado na Saúde. São Paulo: Hucitec, 2005. p. 11-126.

POLLAK, M. Memória, Esquecimento, Silêncio. In: Estudos Históricos, 2. Rio de Janeiro, 1989.

RIBEIRO, A. P. G. Mídia e história: ambigüidades e paradoxos. [S.l.: s.n.], 1998. Disponível: http://www.portcom.intercom.org.br/pdfs/b2da7d98bc2eaf68a3608f5b0a1f4a2a.PDF. Acesso em: 03/06/2018.

A história do seu tempo: a imprensa e a produção do sentido histórico. Dissertação de mestrado. Rio de Janeiro, ECO/UFRJ, 1995.

. A mídia e o lugar da história. IN: HERSCHMANN, M. e PEREIRA, C. Alberto M. Mídia, memória e celebridades: estratégias narrativas em contextos de alta visibilidade. Rio de Janeiro: E-Papers: 2005 [2003].

RIBEIRO, A. P. G. e FERREIRA, L. M. A. (orgs.). Mídia e Memória: a produção de sentidos nos meios de comunicação. Rio de Janeiro: Mauad X, 2007.

RICOUER, P. La memoria, La historia, El olvido. Madri: Trotta, 2003.

Tempo e Narrativa. Campinas: Papirus, 1994, Vol. 1.

ROUSSO, H. Face au passé. Essai sur la mémoire contemporaine. Paris, Belin, coll. Histoire, 2016.

TEIXEIRA, S. F. O Dilema da Reforma Sanitária Brasileira. In: Berlinguer, Giovanni; Teixeira, S. Fleury; Campos, G. W. de S.. Reforma sanitária: Itália e Brasil. São Paulo: Editora Cebes; Hucitec. p.195-207. 1988. 
ZELIZER, B. e TENENBOIM-WEINBLATT, K. (Eds.). Journalism and memory [ebook]. Nova York: Palgrave Macmillan, 2014.

Site consultado: https://radis.ensp.fiocruz.br/index.php/programa-radis 